\title{
Design, development, and learning in e-Textbooks: what we learned and where we are going
}

\author{
Xiaoqing Gu $\cdot$ Bian Wu $\cdot$ Xiaojuan Xu
}

Received: 29 August 2014/Revised: 3 December 2014/Accepted: 4 December 2014/

Published online: 25 December 2014

(C) Beijing Normal University 2014

\begin{abstract}
In the last decade, the use of e-Textbooks has received attention in research and practice. However, the expanded use of e-Textbooks was not easily achieved because of the missing standards in learning content and functionalities, and barriers in utilizing e-Textbooks, such as screen reading and intellectual property protection. This paper provides insights on the design, development, and learning with e-Textbooks by reviewing studies, project reports, and cases on its use. Results reveal the increased promotion and implementation of e-Textbook development in several countries. Criticisms on different e-Textbook types began during the early stages of open multimedia learning resources and digitized textbooks, and continued until the integration of information and communication technologies, authoring tools, and learning platforms. The study examined advantages of e-Textbooks and different factors that influenced e-Textbook applications. The study also reviewed the literature on learning through e-Textbooks in terms of acceptance and perception of users, and the comparison of the learning effectiveness of this format with printed textbooks. Moreover, learning in e-Textbooks is not fully realized, and requires increased indepth studies. This paper suggests investigating the pedagogical design of e-Textbooks and further evaluation of e-Textbook functions to support learning.
\end{abstract}

Keywords E-Textbook - Development · Functionality · Acceptance · Pedagogical design

\section{Introduction}

The rapid adoption of iPads, tablets, and e-book readers as personal digital devices in the education systems around the world has been observed recently. In Shanghai,

X. Gu $(\bowtie) \cdot$ B. Wu $\cdot$ X. Xu

Department of Educational Information Technology, East China Normal University, 3663

Zhangshan Road North, Shanghai 200062, China

e-mail: xqgu@ses.ecnu.edu.cn; guxqecnu@gmail.com 
over two million students in $2000 \mathrm{~K}-12$ schools are required to use the "eschoolbag," which consists of a small personal computer (Gu 2011). Similarly, the classroom phenomenon of maintaining a 1:1 ratio of device per student is rapidly spreading in elementary school classrooms in Taiwan, and to elementary classrooms around East Asia (Chan 2010). As personal learning devices become accessible to learners, the mode of e-learning also changes. The personal device has emerged as a learning platform, and the e-Textbook has evolved as the corresponding learning interface with tools and services available from within the platform and from external connections.

As the metaphorical textbook, an e-Textbook is the equivalent of the printed textbook in the electronic schoolbag, a general term for all of the digital learning devices. Hence, the e-Textbook becomes an integral component of an electronic schoolbag and a main learning resource. The e-Textbook can be more advanced in its transition from traditional printed textbook to e-Textbook, as it integrates multimedia and contains more interactive functions (Choi et al. 2011; Lee et al. 2013; Reynolds 2011). An e-Textbook can be conceived as a platform for learning that combines e-learning and e-publishing technologies, and serves as a dynamic and interactive reading material, and as an interface for learning activities among learners and the learning communities. Learners can personalize their own text by writing notes, highlighting, and combining related sections together based on their understanding and prior knowledge. Many studies use different terms such as digital-Textbook, electronic textbook or e-Textbook to refer to the similar concepts (Choi et al. 2011; Daniel \& Woody 2013; Kim et al. 2010b; 2013; Liu 2012; Luik and Mikk 2008; Rockinson-Szapkiw et al. 2013; Weisberg 2011). In this review study, we deem these terms as synonyms and use e-Textbook consistently.

For several years, the increased widespread use of e-Textbooks in education has been anticipated because of its flexibility, accessibility, interactivity, and extensibility (Daniel and Woody 2013; Murray and Perez 2011; Nelson 2008a, b; Woody et al. 2010). However, the anticipation has not come to fruition. Although e-Textbooks have drawn wide attention, the missing standards of learning content and functionalities and barriers in the use of e-Textbooks (i.e., screen reading, licensing restrictions) are among the problems that require solutions (Liu 2012; Nelson 2008a, b; Reynolds 2011; Yuen et al. 2012). Besides, how e-Textbook affects teaching and learning remains unclear. Therefore, this review article looks into the current studies and projects on the design, development, and learning with respect to e-Textbooks with the intention of clarifying the key requirements for e-Textbooks' functionality and investigating the learning impacts of adopting e-Textbooks.

This article is organized as follows. "Methodology" section describes the methodology that was utilized to obtain the sources for the review. "E-Textbook projects around the world" section presents an overview of existing projects on e-Textbooks. "Design, development, and experiments on e-Textbooks" section presents general opinions on the widening spread of e-Textbooks. "Discussion" presents an in-depth review of the design and development of e-Textbooks and related empirical studies. In conclusion, this article provides a discussion on the directions for research and practice on the subject. 


\section{Methodology}

We selected a mixture of empirical studies that focused on the design, development, and learning with e-Textbooks that were conducted around the world during the last decade. Employing databases, such as ScienceDirect, Web of knowledge, EBSCO, SpringerLink, Wiley Online Library, and GoogleScholar, we searched using several keyword combinations including "e-textbook," "electronic textbooks," "digital textbook," "design," "development," and "learning." We utilized the snowball method to select additional articles from the references of the reviewed papers, and ruled out articles that were nonempirical descriptions of e-Textbook projects and opinion papers on this topic. In total, we examined 43 articles that reported empirical findings on the design, development, and learning with e-Textbooks.

In collecting the cases on the use of e-Textbooks, we initiated two rounds during which we called for e-Textbook use cases with the ISO/IEC/JTC 1/SC 36, as part of the study on the key requirements for e-Textbook functionality for Project 18120 (ISO/IEC JTC1/SC36 WG6 2013). These two rounds of calls lasted for approximately one and a half years, with the first round held from September 2010 to August 2011, and the second, from March to September 2011. This period resulted in 55 e-Textbook use cases (ISO/IEC 2010; 2012a). These cases were submitted by the national bodies of ISO/IEC/JTC 1/SC 36, including the UK, Canada, Australia, France, China, Korea, and Kenya, and were received from e-Textbook organizations, such as the International Digital Publishing Forum (IDPF) and Open Educational Resources (OER) programs.

In collecting the project reports, we searched project websites and selected representative projects that presented the current situation in e-Textbook pioneer countries, such as Singapore, Korea, and the UK, from 1999 to present. These reports included completed and ongoing e-Textbook projects, with a focus on the design and development as well as the comprehensive purposes behind e-Textbooks.

Three educational researchers examined 53 empirical studies and conducted content analysis by summarizing major themes of these materials. Five categories could cover almost all topics under investigation. These categories include e-Textbook typology, e-Textbook features and its advantages, user acceptance of e-Textbook, effectiveness of e-Textbook in support of learning, and learning design of e-Textbook. Each category was analyzed to identify the lessons, experiences, and best practices on the design, development, and learning with e-Textbooks. In addition, 18 project reports were analyzed to illustrate the global picture of e-Textbooks. Fifty-five use cases were related to the functional requirements, and were classified into development for further analysis. Table 1 presents the breakdown of our data. Utilizing the constant comparative method on these articles and cases, we derived the key findings and requirements on e-Textbooks. The following paragraph will present a overview of e-Textbook project from all around the world, followed with meta-analysis results of studies and cases. 
Table 1 Reviewed articles, use cases, and project reports

\begin{tabular}{lllll}
\hline Source & Design & Development & Applications & General studies \\
\hline Empirical articles & 8 & 15 & 23 & 7 \\
Cases & & 55 & 8 & \\
Project reports & 3 & 7 & & \\
\hline
\end{tabular}

\section{E-Textbook projects around the world}

E-Textbooks gained popularity in the previous years. Over 20 countries utilize e-Textbooks in their education systems. This section reviews several projects that focused on the development and implementation of e-Textbooks in different countries, including Singapore, UK, US, South Korea, Japan, France, and Malaysia (see Table 2).

\section{Design, development, and experiments on e-Textbooks}

The design, development, and the experiment conducted on e-Textbooks are reported in this section. Different types of e-Textbooks, from primitive digitization of learning content to sufficiently utilizing interactive technologies, as well as their development are presented. A review of the experiments on e-Textbooks and a discussion on the learning designs in using e-Textbook follow.

How e-Textbooks are produced: types and development

Based on our investigation for the study period report in preparing the e-Textbook standard proposal (ISO/IEC JTC1/SC36 WG6 2012b), over 30 different e-book formats are available. At least five of these formats are mainstream, namely, TEXT, HTML, CHM, PDF, and EPUB. These are also, currently, the most frequently used formats in developing e-Textbooks.

By examining the collected use cases, three different manifested types of e-Textbooks, including multimedia learning materials and its recent manifestation as applications (APPs), e-books, and open online e-books, such as wiki, were identified. Similarly, e-Textbooks were categorized into web-based, reading software-based, and device-based (Abdullah 2007; Vassiliou and Rowley 2008; Lee, Messom and Yau 2012).

In its early stage, the e-Textbook was a supplementary multimedia learning resource, rather than as a stand-alone replacement of printed textbooks. This type of e-Textbook was developed with multimedia software or html, and delivered through a website or CD-ROMs (Dennis et al. 2012). For example, in the early stage of e-Textbook development in Korea, e-Textbooks were designed as supplementary materials for printed textbooks (Kim et al. 2010a). Similarly, in China, early versions of e-Textbooks were developed into multimedia learning packages or courseware solutions as supplementary materials of paper textbooks (ISO/IEC 


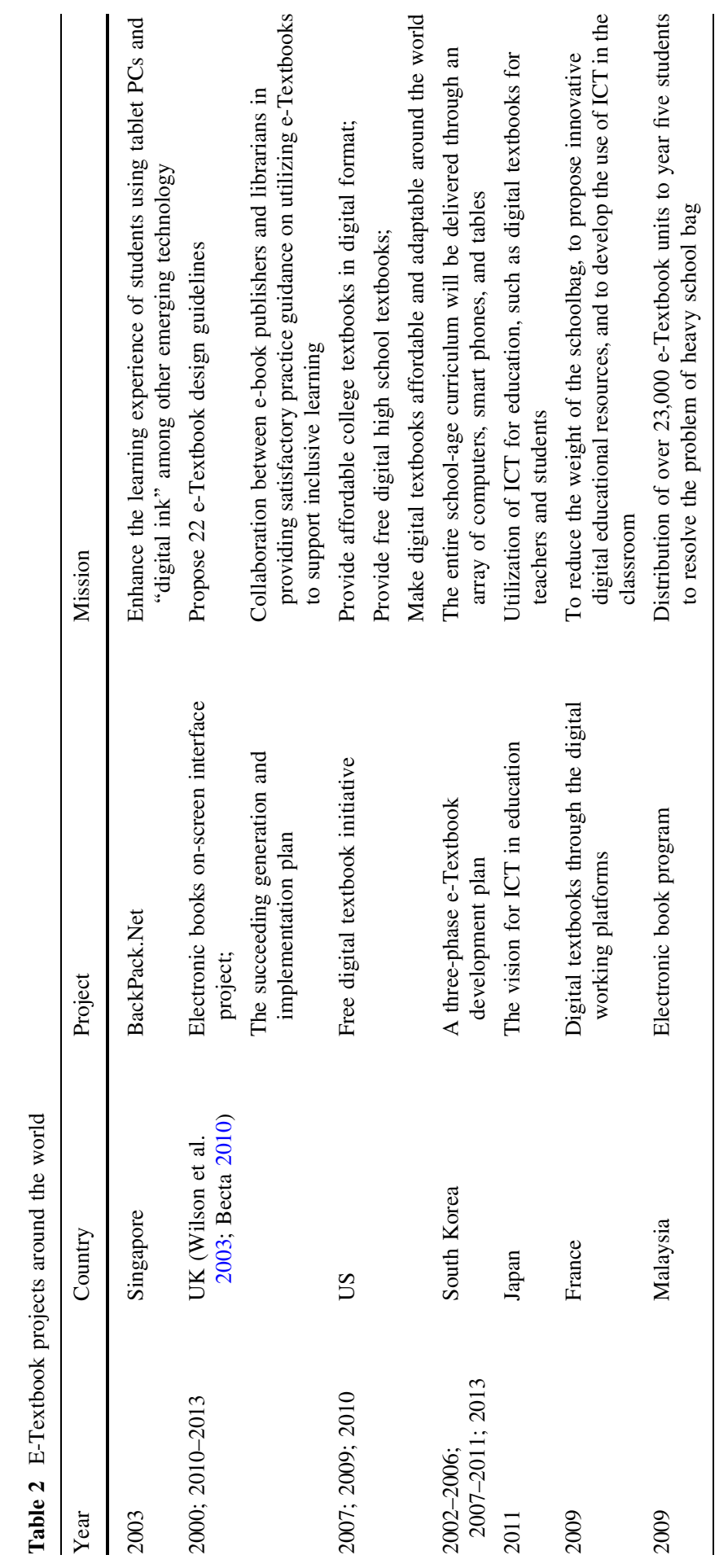


JTC1/SC36 WG6 2012b). This finding is also the case for early e-Textbook projects, such as CeLCAR Projects (2005), Learn (2010), and Texas Politics (2008). Although this approach to e-Textbook catered to learning advantages, the development costs were quite high, and the multimedia materials were difficult to update along with printed textbooks (ISO/IEC JTC1/SC36 WG6 2013a, b). With the popularization of mobile devices, APPs started to replace multimedia learning packages as the current version of e-Textbooks.

Open online book was another "old-fashioned" approach in developing e-Textbooks based on our collected use cases and the reviewed literature. For example, cases from the OER projects demonstrated that an online open source was regarded as a type of e-Textbook. The use case of "Teacher Generated E-Book" from the UK originated from an open learning content platform, where teachers, education institutions, and national agencies gathered the content to construct an e-book that supported their learners and contributed to the global OER (ISO/IEC JTC1 SC36 WG6 2013a, b). Similarly, the "Digital Futures Project" developed an open textbook on Digital Literacy in Education, which is an open resource (100,000 words) undertaken as part of the third phase of the HEA/JISC UK OER program. The program involves two universities, regional schools, and the Regional Broadband consortium (ISO/IEC JTC1 SC36 WG6 2013a, b). Content management systems, such as Wordpress, are commonly used to develop this type of e-Textbook as well.

The literature reported the production of open online books to maximize the rich free information on the web. Chen et al. (2005) advocated a novel approach in automatically generating an e-Textbook from mining and assembling web pages that were "suitable" for particular learning topics and processes. The contents of the e-Textbook were free, accessible web pages that teachers and students can utilize in preparing teaching materials and exploring their interests, respectively. This trend of open textbook strategy has been recognized as the promising solution to tackle the problems of the conventional form of textbooks, and in developing e-Textbooks in Hong Kong as cited in Li et al. (2012). Except for the advantage in making full use of the free and rich learning resource on the web (Chen et al. 2005; Cheung et al. 2012), the promise of open online textbook solution is that it can overcome the frequently mentioned issues of e-Textbooks, such as copyright hurdles (Yuen et al. 2012), frequent updates (Cheung et al. 2012), and the pressing issues of high prices of paper textbooks (Li et al. 2012; Cheung et al. 2012).

A widely recognized method of developing e-Textbooks, which is also the easiest way, was to digitalize existing printed books as replacement textbooks, especially in the context of higher education. For example, the use case from the Kenya National Library Service (KNLS) introduced the process of digitizing hard copies to e-Textbooks to ensure that they are widely accessible (ISO/IEC JTC1 SC36 WG6 2013a, b). By transforming textbooks from paper to electronic means, leveraging technology to benefit students in cost-savings and learning was expected (Briske et al. 2011; Young 2010). Originally, this kind of e-Textbook project just aimed to digitalize printed books without adding interactive technologies, and was far cheaper to produce than printed texts. At present, major publishers, like the McGraw-Hill Companies, Pearson, and John Wiley \& Sons, are offering digitalized 
versions of their books (e.g., PDF), while universities are proposing a switch to e-Textbooks to be more affordable for all students (Young 2010).

Along with the e-Textbook development track, e-books are produced for the portable deliveries to new devices, such as Kindle and iPad (e.g., Rickman et al. 2009). This platform usually convert paper textbooks into digital forms (Lee et al. 2012), which appear in a wide range of formats, such as HTML, XML, ACW, and EPUB.

Although easy to produce, this type of e-Textbook is limited to the contents of printed textbooks, which lacked additional learning functionalities. Considering that this type of e-Textbook does not separate document content and style, functions like searching and linking, and interactivity and learning support are limited (Kim et al. 2010a; Dennis et al. 2012; ISO/IEC JTC1/SC36 WG6 2013a, b). As a result, projects that capitalized on these e-Textbook types were met with minimal success and even failure, including the MalayBook project in Malaysia that replaced paper textbooks with e-Textbooks without supported learning functions (Kim et al. 2010a; Lee et al. 2012).

The latest stage in developing e-Textbooks involved rethinking what a textbook should be, and incorporating the benefits of various types of ICT technologies (ISO/ IEC JTC1/SC36 WG6 2013a, b; Kim et al. 2010b). For example, international organizations such as IDPF, creative commons, GEN, and ISO are undertaking their e-Textbook projects, either to upgrade their previous e-books to include educational features (such as EPUB), or to strengthen e-learning products to include growing e-reading materials (such as ISO, GEN, and creative commons).

The International digital publishing forum (IDPF) is a global standard organization dedicated to the development and promotion of e-publishing. IDPF considered educational elements, such as content and workflows, learning objects and remixing, and integration issues, such as integration of e-Textbooks into the overall online learning environments and other web services, annotations and social integration, learners, and accessibility (ISO/IEC JTC 1/SC 34 2013a, b). In line with these considerations, the EPUB standard that was not originally dedicated to the e-Textbook is being updated to meet the flexibility, interactivity, and extensibility from educational contexts. In our current effort in Project 18120, the key requirements of e-Textbooks should include a foundational e-book standard, extend the annotation functions, support the function of re-organizing and re-sequencing content chunks, and should support different kinds of rich media and interactive controls (ISO/IEC JTC1 SC36 WG6 2013a, b).

Moreover, industries and researchers proposed new ways of developing e-Textbooks during this stage. Industries are eager to provide the authoring tools to produce e-Textbooks by updating the publishing systems or platforms. These updates include functions, such as object-oriented content management and customized and device-specific layout, which facilitate the ease of creating multimedia and interactive elements. Authoring tools, such as iBooks Author ${ }^{1}$ and Articulate Storyline, ${ }^{2}$ provide basic functions for end users to create e-Textbooks,

\footnotetext{
${ }^{1}$ http://www.itunes.apple.com/us/app/ibooks-author/id490152466.

2 http://www.articulate.com/products/storyline-overview.php.
} 
whereas, several commercial products are also available for publishers or other interested parties to produce e-Textbooks, by reinventing the publishing industry.

Researchers, on the other hand, are more concerned with providing functions that are necessary for learners and instructors. For example, to facilitate the interoperability of users with e-Textbooks, Kim et al. (2010b) proposed an XML-based digital textbook solution that integrates the advantages of printed textbooks with digital media. The design included supplementary information to display the content that users create by using the e-Textbook, along with the original fundamental information. With the intention of using the ICT interactive features, Choi et al. (2011) proposed an approach in developing e-Textbooks, which differentiated learning from regular teaching. By working with the publisher, Defazio (2012) appropriated the e-Textbooks to his class, which consequently made these resources affordable for his students.

What features are valued: advantages of e-Textbooks

The distinct advantages of e-Textbooks in class enumerated in studies include the abilities to store large amounts of materials, high-quality screens with backlighting for reading, light weight, easy-to-use, fun-learning process due to attractive features, more economic, and greater support to monitoring classroom activities (Embong et al. 2012a, b; Simon 2001).

In addition to the advantages of e-Textbooks, researchers explored what features of e-Textbooks students often used and valued most, and the extent they took advantage of those features. Some of the most frequently used features include the glossary lookup and annotation, bookmarking, highlighting, and searching (McFall et al. 2006; Simon 2001). Learners perceive e-Textbooks with annotations and sharing capabilities supportive to learning (Lim and Hew 2013). Through their careful evaluation of three versions of a designed e-Textbook, Wilson et al. (2003) found that users want some features of paper books to be preserved in the electronic medium, while preferring electronic texts to be written in scannable style.

Several challenges in the use of e-Textbooks were also identified and addressed to enhance learning. Students found that e-Textbooks often entailed a short loan period, while e-Textbook software was often cumbersome to install with a marked lack of technical support (Embong et al. 2012a, b). Poor user friendliness and text displays that were more suitable for paper medium (Kropman et al. 2004) were cited as problems in the use of e-Textbooks. In class instruction, limited power outlets in the classroom for e-Textbook devices, inadequately trained teachers on the use of e-Textbooks for teaching, and insufficient supply or limited access to e-Textbooks (Embong, et al. 2012a, b) were noted as problems. Further, the successful adoption of e-Textbooks required schools to provide necessary resources, such as computer labs and instructors, to engage students actively in using e-Textbooks (Sun et al. 2012).

How people like it: acceptance of e-Textbooks

User acceptance of e-Textbooks is one of the most frequently investigated topics of empirical studies. Perceptions and attitudes of users toward e-Textbooks were 
identified two aspects of the studies. The first aspect is that studies examined user preferences for paper and e-Textbooks. The second aspect is that studies discussed user perceptions. Other results indicated that the cognitive load compared the comprehension of electronically displayed texts with the comprehension of texts displayed conventionally on the printed page.

E-Textbooks offer a promising alternative for students because of their cheaper cost than traditional books. Allen (2008) and Martin (2009) report that students will opt for the cheaper e-Textbook offer, and consider open and free textbooks without restrictions. A similar survey found that almost $80 \%$ of all the 500 studentrespondents said they would opt for the cheaper e-Textbook if they needed to buy the textbook themselves (Martin 2009). Weisberg (2011) examined student attitudes and behavior toward the use of e-Textbooks relative to traditional paper textbooks and the potential impact of e-Textbooks on student learning. Findings suggested that student attitude and behavior were receptive to and accepting of using digital textbooks. The major factors affecting their acceptance of e-Textbooks are cost, impacts on learning, and instructor support.

Accessibility is another frequently mentioned factor that positively influences the fast spread of the popularity of e-Textbooks. Based on a comprehensive research conducted by Reynolds (2011), accessibility of e-Textbooks, such as the popularity and evolution of tablet devices and smart phones, was a strong factor in the wide adoption of e-Textbooks. Allen (2008) makes a similar claim, and notes that once students buy digital textbooks, they will be able to access them online, store them for use offline, and keep a copy for future use. Embong et al. (2012a, b) conducted a survey among 72 teachers who used e-books as textbooks. Majority of the respondents expressed satisfactory perceptions on the use of e-books. Both teachers and students began to value the convenience and accessibility of e-Textbooks. The minimal problems that the teachers reported on using the device can be overcome with strategies and a suggested framework.

However, some other scholars indicated that user acceptance of e-Textbook was not very encouraging. For example, McGowan et al. (2009) conducted a survey to examine student preferences regarding paper and electronic textbooks and found that students of all ages and experience levels overwhelmingly preferred paper textbooks to e-Textbooks. Still, students perceived cost, weight, and ability to highlight and take note to be the advantages of e-Textbooks over paper-based textbooks. Similarly, Woody et al. (2010) examined factors influencing preference for e-books and the reported use of the e-book content. The results showed students did not prefer e-Textbooks to textbook regardless of their gender, computer use, or comfort with computers. No significant correlations existed between the number of e-Textbooks previously used and the overall preference of e-Textbooks as participants who had previously used an e-Textbook still preferred print texts for learning. Besides, the expected benefits of e-Textbook in terms of strong visual and interactive elements do not seem to be used. The authors argued to further investigate the user experience of and interaction with e-Textbook. Elias et al. (2012) conducted a survey of students and faculty at a school of pharmacy to identify the availability and interest in the adoption of e-Textbooks. They found that students and faculty at this school of pharmacy apparently were not interested in 
adopting e-Textbooks at that time due to necessity of textbooks for in-class use and unfamiliarity with e-Textbooks. Liu's study (2012) revealed that screen reading and licensing restrictions were the most perceived barriers of using e-Textbooks.

To sum up, various factors may affect acceptance and preference of using e-Textbooks, such as comfortable reading experience, reading habits, cost, familiarity of e-Textbook functions, accessibility, to name but a few. Meanwhile, most scholars acknowledged that e-Textbooks have the potential to complement print textbooks and broaden their use in the near future only if some identified hurdles can be solved.

\section{Does it work: effects on learning}

In addition to user acceptance of e-Textbooks, empirical studies also focused on the effects of e-Textbooks on student learning. Most studies compared student comprehension of texts displayed electronically with texts displayed conventionally on printed pages. Findings revealed that texts displayed in electronic and print had no significant difference on learning performance. For example, Some scholars examined the perceptions and performances of students who used electronic versus traditional textbooks, and found no difference in learning performance (Shepperd et al. 2008; Murray and Perez 2011; Daniel and Woody 2013). Rockinson-Szapkiw et al. (2013) found that the e-Textbooks were as effective for learning as the print textbooks. Further, their findings revealed that students who chose e-Textbooks for their education courses had significantly higher perceived affective and psychomotor learning than students who chose to use traditional print textbooks. These studies suggested e-Textbooks were at least comparable to, if not better than, print textbooks in terms of learning effectiveness.

An intriguing finding suggested that participants who used e-Textbooks with annotations outperformed those using print textbooks. However, learners perceived e-Textbooks as worse in meeting their learning needs (Dennis et al. 2012). These findings indicated that participants do not immediately recognize the value of using e-Textbooks. The study suggested that instructors should assist students in adapting their study processes to the new technology, as well as in preparing for an initial stage of dissatisfaction with e-Textbooks.

Some scholars argued that student performance was better when reading texts on printed pages under certain conditions (Ackerman and Goldsmith 2011; Ackerman and Lauterman 2012; Mangen et al. 2013). When study time was self-regulated, the better performance was observed in reading on paper than on a screen, although no differences on test performances were derived between the two media under fixed study times (Ackerman and Goldsmith 2011). In another study by Ackerman and Lauterman (2012), undergraduates reported a moderate preference for paper over screen reading under time constraints. Results reinforced the inferiority of selfregulation in learning on screen, and argued against technology-related factors as the primary reason behind the poor performance. In addition, Mangen et al. (2013) explored the effects of the technological interface on the reading comprehension of Norwegian students, and found out that the reading comprehension of students who 
read texts on print was significantly higher than students who read the texts digitally.

One important factor called cognitive load draws special attention by researchers of e-Textbook. Cognitive load refers to mental effort during complex learning activities such as reading and knowledge understanding. Measurement of cognitive load in reading e-Textbooks versus printed textbooks indicated significant differences in reading time and self-reports of multitasking (Daniel and Woody 2013). Hao (2013) investigated middle-school students mental effort when they read e-Textbook in an English-as-a-Second-Language classroom and found that they took below-medium mental effort for searching for pages and above-medium mental effort for comprehending the book content. Liu (2005) suggested that a person's ability to remember where a certain passage was found in a print-based book is an ability that does not appear to transfer to the electronic text. More research is needed to study the cognitive load in reading e-Textbooks to confirm those claims.

Researchers who focus on time spent on reading e-Textbooks obtained conflicted findings. Shepperd et al. (2008) found students spent less time reading e-textbooks for class than those who were reading print textbooks, and inferred that e-Textbooks may help students achieve the same grade with lesser time. Woody et al. (2010) reported that reading time was significantly higher in electronic conditions than in paper conditions. However, both studies cautiously indicated that abandoning the print textbooks in favor of the e-Textbooks is still premature.

How to use it: learning designs of e-Textbooks

After clarifying the expectations for e-Textbooks, this part focused on the learning design with e-Textbook. Quite a few case and experimental studies focused on design issues, such as the pedagogical framework design for e-learning. Developing e-Textbooks requires embedding innovative ICT into curriculum, such that the approaches to the design of pedagogical framework for e-learning can be used as reference. This section recommends proper approaches to the instructional and technological design of e-Textbooks, which are proven to be effective for learning in an e-learning context.

Spanovic (2010) proposed a systematic approach for the conceptual design of e-Textbooks, which supported optimal individualization, encouraged discovery learning based on student activities, and considered the advantages in using this medium. However, detailed instructional design and practice to inform how those goals can be achieved are lacking. The pragmatic problem was noted in Railean (2012) with the argument that e-book pedagogy aims not only to represent, but also to generate knowledge and support for the interdependence of cognitive, affective, and psychomotor objectives. The author proposed a metasystem design framework of the four elements that included e-learning context methodology, motivation, performance, and assessment. The framework should follow the principles of selfregulation, personalization, clarity, dynamicity, flexibility, feedback diversity, and ergonomics. 
Similarly, Embong et al. (2012a, b) proposed six principles in designing e-Textbooks. These principles included offering various presentations of information and activities, facilitating the evaluation of student work, automating feedbacks for students, providing scaffolds for the learning process, and ensuring sustainable resources of knowledge. By analyzing and comparing two e-Textbook designs, Crestani et al. (2006) provided guidelines to integrate the two main dimensions of e-Textbooks, namely, appearance and functionality.

The increase in practical instructional strategies included integrating visual cue maps into e-Textbook software and providing reading strategies, i.e., surveying and questioning ( $\mathrm{Li}$ et al. 2013). Offering authoring tools for instructors to customize the learning objects and annotation and note-taking tools for students to personalize textbook materials could facilitate the merging of teaching and learning in an integrated educational environment (Adamchik and Gunawardena 2005). Providing a modest number of instructor annotations and multimedia instructional videos embedded in the e-Textbooks was deemed to improve student learning (Dennis et al. 2012). All these strategies highlighted a distinctive feature of e-Textbooks that supported personalized learning.

Further, Luik and Mikk (2008) differentiated the use of e-Textbooks between learners with different achievement levels, and claimed that low-achieving students benefited from the features of the e-Textbooks. These features include clear instructions, familiar icons, examples, and answering from the keyboard. High-achieving students benefited from the richness of navigation possibilities (key-combinations, multi-level menus) and analogies, as well as Internet connectivity and lower term density on material content. Findings suggested that the design of e-Textbook tools should vary depending on the level of learner achievement.

To date, e-Textbook designs focus on the interface and technical aspects to improve user acceptance. The instructional principles and strategies for e-Textbooks have yet to be widely and systematically evaluated. Research on e-Textbook design is still at its infant stage. The pedagogical design needs more attention in terms of how e-Textbooks can be designed to afford teaching and learning in a more effective way and in the impact of specific e-Textbook designs on learning performance.

\section{Discussion}

The consensus that e-Textbooks have widely spread across the world and educational levels was established. From the practical perspective, e-Textbook projects were initiated in the education systems of at least 20 countries, and were regarded as learning resources relative to the context. From the research perspective, potentials for learning have been indicated, while the pedagogical design of e-Textbooks and the evaluation of e-Textbook functions in support of learning need further investigation.

By reviewing the use cases and study reports, this research concludes that understanding of and the basic functions provided within an e-Textbook context 
have yet to emerge from the interested parties. From the analysis, the development of the e-Textbook has progressed along with the acceptance of using an e-Textbook. Three different manifested types of e-Textbooks are currently designed, developed, and utilized in different educational contexts. These types, applications, and integrated online platforms are either more widely recognized or more easily produced. However, obtaining the consensus among various stakeholders in e-Textbook development remains unlikely in the near future. Therefore, endeavors in developing e-Textbook standards are highly necessary to define the key requirements for e-Textbooks, along with adapting to the different efforts of industries and researchers who have proposed novel approaches in developing different types of e-Textbooks. For end users, attention on the necessary functions for an e-Textbook, and achieving these functions in the design and development of an e-Textbook, with easy-to-use authoring should be increased.

Empirical studies reflect that the e-Textbook features, user acceptance, learning effectiveness, and appropriate pedagogical design in learning with e-Textbooks are the most frequently investigated topics. The analysis of e-Textbook features indicated that, while there are advantages of e-Textbooks that have been valued by users, many of these advantages, such as visual and interactive elements, have yet to be recognized with better learning designs. Meanwhile, challenges needed to be addressed to make full use of this new technology, such as better interface design and institutional support.

As user acceptance and learning effectiveness of e-Textbooks are concerned, further in-depth studies are required to determine the conditions and features that users will yield positive learning results. Currently, findings on user acceptance and effectiveness are generally contradictory. While some studies on user acceptance claim that students and teachers do not prefer e-Textbooks, other studies reveal that users express satisfactory perceptions on the use of e-Textbooks over printed books. Preliminary investigation indicates that if the functions of e-Textbooks are well designed, the results of user attitude and behavior toward the use of e-Textbooks relative to traditional paper textbooks will be more encouraging.

Similar contradictory findings are derived in determining the learning effectiveness of e-Textbooks, but still, some findings yield no significant effect while others indicated a degree of effectiveness. Such that using e-Textbooks is regarded as a common multi-tasking activity. Failing to consider this, the comparison between e-Textbooks and printed books will be biased. Therefore, further investigations into the use of e-Textbook and its effectiveness should look into the functions of an e-Textbook (what an e-Textbook can provide), as well as the conditions (environment, learning conditions) for an e-Textbooks use, and the potential that an e-Textbook can realize.

The e-Textbook designs often focus on the interface and the technical aspects to improve user acceptance. Instructional principles and strategies for e-Textbooks are not widely and systematically evaluated. The research design of e-Textbooks is still at its infant stage. The pedagogical design requires increased attention on e-Textbook designs to make teaching and learning more effective, and the impact of specific e-Textbook designs more extensive on learning performance. 


\section{Conclusion}

The study provides insights on the design, development, and learning with e-Textbooks by reviewing studies, project reports, and cases on its use. The pertinent questions asked what we know today about the design, development, and learning with e-Textbooks, and what the potentials for research and practice are. Results reveal the increased promotion and implementation of e-Textbook development in several countries. Criticisms on different e-Textbook types began during the early stages of open multimedia learning resources and digitized textbooks, and until the integration of Information and Communication technologies, authoring tools, and learning platforms. Various scenarios on the uses and advantages of e-Textbooks, and the different factors influenced e-Textbook applications. Studies on learning through e-Textbooks focus on the acceptance and perception of users, and the comparison of the learning effectiveness of this format with printed textbooks. Moreover, learning in e-Textbooks is not fully realized, and requires increased in-depth studies. This paper suggests investigating the pedagogical design of e-Textbooks and further evaluation of e-Textbook functions to support learning.

Acknowledgments This study is supported by the Program for New Century Excellent Talents in University (NCET NCET-11-0140). The authors are very grateful to the anonymous reviewers for their insightful and knowledgeable comments and constructive suggestions.

\section{References}

Abdullah, N. (2007). A study into usability of tools for searching and browsing e-books with particular reference to back-of-the-book index, $P h D$ dissertation, University of Strathclyde.

Ackerman, R., \& Goldsmith, M. (2011). Metacognitive regulation of text learning: On screen versus on paper. Journal of Experimental Psychology: Applied, 17(1), 18-32.

Ackerman, R., \& Lauterman, T. (2012). Taking reading comprehension exams on screen or on paper? A metacognitive analysis of learning texts under time pressure. Computers in Human Behavior, 28(5), 1816-1828.

Adamchik, V., \& Gunawardena, A. (2005). Adaptive book: Teaching and learning environment for programming education. Paper presented at the international conference on information technology: Coding and computing.

Allen, N. (2008). Course correction: How digital textbooks are off track, and how to set them straight. Student PIRGs.

Becta. (2010). Next generation learning implementation plan for 2010-2013. Technology strategy for further education and skills. Accessed December 23, 2013, from http://www.dera.ioe.ac.uk/11052/1/ implementation_plan.pdf.

Briske, K., DeMonner, S., Emery, L., Folger, K., Hollar, S., Kuffner, K., Leasia, J., McDowell, S., \& Nicholls, N. (2011). E-Textbook working group summary of activities for April 2010-June 2011 and recommendations. Accessed December 23, 2013, from http://www.lib.umich.edu/files/EtextWGRecommendations+Report-June2011.pdf.

Crestani, F., Landoni, M., \& Melucci, M. (2006). Appearance and functionality of electronic books. International Journal on Digital Libraries, 6(2), 192-209.

CeLCAR projects. (2005). Indiana University. Accessed December 23, 2013, from http://www.indiana. $\mathrm{edu} / \sim$ celcar/media/project/project.html.

Chan, T. W. (2010). How East Asian classrooms may change over the next 20 years. Journal of Computer Assisted learning, 26(1), 28-52. 
Chen, J., Li, Q., \& Jia, W. (2005). Automatically generating an e-textbook on the web. World Wide Web: Internet and Web Information Systems, 8, 377-394.

Choi, J., Heo, H., Lim, K., \& Jo, Il. (2011). The development of an interactive digital textbook in middle school English. In T.-h. Kim et al. (Eds.), FGIT 2011, LNCS 7105 (pp. 397-405). Berlin Heidelberg: Springer-Verlag.

Creative commons. (2013). Open textbooks. Accessed December 23, 2013, from http://www. creativecommons.org/tag/open-textbooks.

Cheung, S., Yuen, K.S., Li, K.C., Tsang, E., \& Wong, A. (2012). Open access textbooks: Opportunities and challenges. In K.C. Li et al. (Eds.), ICT 2012, CCIS 302 (pp. 201-210). Berlin Heidelberg: Springer-Verlag.

Daniel, D. B., \& Woody, W. D. (2013). E-Textbooks at what cost? Performance and use of electronic v. Print texts. Computers \& Education, 62, 18-23.

Defazio, J. (2012). Challenges of electronic textbook authoring: Writing in the discipline. In T.-h. Kim et al. (Eds.), EL/DTA/UNESST 2012, CCIS 352 (pp. 8-14). Berlin Heidelberg: Springer-Verlag.

Dennis, A. R., McNamara, K. O., Morrone, S., \& Plaskoff, J. (2012). Improving learning with etextbooks. Accessed December 23, 2013, from http://www.etexts.iu.edu/files/Improving\%20learning\% 20with\%20etextbooks.pdf.

Elias, E. C., Phillips, D. C., \& Luechtefeld, M. E. (2012). E-books in the classroom: A survey of students and faculty at a school of pharmacy. Currents in Pharmacy Teaching and Learning, 4, 262-266.

Embong, A. M., Noor, A. M., Ali, R. M. M., Bakar, Z. A., \& Amin, A. R. M. (2012). Teachers' perceptions on the use of e-books as textbooks in the classroom. In Proceedings of World Academy of Science, Engineering and Technology.

Embong, A. M., Noor, A. M., Hashim, H. M., Ali, R. M., \& Shaari, Z. H. (2012b). E-Books as textbooks in the classroom. Procedia: Social and Behavioral Sciences, 47, 1802-1809.

Gu, X. (2011). Educational technology plan in Shanghai: Towards developing every child and for their lifelong development. E-education Research, 2, 5-10. (in Chinese).

Hao, Y. (2013). Effects of E-Textbooks on student mental effort in an ESL middle school classroom. In R. McBride \& M. Searson (Eds.), Proceedings of Society for Information Technology \& Teacher Education International Conference (pp. 2118-2121). Chesapeake, VA: AACE.

ISO/IEC JTC 1/SC 34 (2013) ISO/IEC DTS 30135-1, Information technology-Digital publishingEPUB3-Part 1: EPUB3 overview, Accessed December 24, 2013, from http://www.iso.org/iso/ catalogue_detail.htm?csnumber=53255.

ISO/IEC JTC1/SC36 WG6. (2010). ISO/IEC JTC1 SC36 study period on e-Textbooks: Call for use cases. Unpublished manuscript.

ISO/IEC JTC1/SC36 WG6. (2012a). ISO/IEC e-Textbook call for contributions. Unpublished manuscript.

ISO/IEC JTC1/SC36 WG6. (2012b). Information technology for learning, education, and training study period report of e-Textbook standard NWI proposal. Unpublished manuscript.

ISO/IEC JTC1/SC36 WG6. (2013). ISO/IEC/JTC 1/SC 36 N 18120: Information technology-Learning, education, and training-e-Textbook. Unpublished manuscript.

Kim, J. K., Sohn, W. S., Hur, K., \& Lee, Y. (2013). Improving usability of educational resources by annotation mechanism. In Proceedings of the 1st International Conference on Convergence and it's Application (pp. 128-130).

Kim, M., Yoo, K. H., Park, C., \& Yoo, J. S. (2010a). Development of a digital textbook standard format based on XML. Advances in Computer Science and Information Technology Lecture Notes in Computer Science, 6059, 363-377.

Kim, M., Yoo, K. H., Park, C., Yoo, J. S., Byun, H., Cho, W., Ryu, J., \& Kim, N. (2010b). An XML-based digital textbook and its educational effectiveness. In T. H. Kim and H. Adeli (Eds.), AST/UCMA/ ISA/ACN 2010, LNCS 6059 (pp. 509-523).

Kropman, M., Schoch, H. P., \& Teoh, H. Y. (2004). An experience in e-learning: Using an electronic textbook. Paper presented at the Beyond the comfort zone: Proceedings of the 21st ASCILITE Conference, Perth.

Learn NC. (2010). North Carolina history: A digital textbook. Accessed August 12, 2013, from http:// www.learnnc.org/lp/projects/history.

Lee, H. J., Messom, C., \& Yau, K. A. (2012). e-Textbooks: Types, characteristics and open issues. Journal of Computer, 4(9), 2151-9617.

Lee, H. J., Messom, C., \& Yau, K. L. A. (2013). Can electronic textbooks be part of K-12 education? : Challenges, technological solutions and open issues. Turkish Online Journal of Educational Technology-TOJET, 12(1), 32-44. 
Li, L. Y., Chen, G. D., \& Yang, S. J. (2013). Construction of cognitive maps to improve e-book reading and navigation. Computers \& Education, 60(1), 32-39.

Li, K. C., Yuen, K. S., Simon, Cheung, K.S., \& Tsang, E. Y. M. (2012). Evolution from conventional textbooks to open textbooks: A way out for Hong Kong. In K. C. Li et al. (Eds.), ICT 2012, CCIS 302 (pp. 211-227). Berlin Heidelberg: Springer-Verlag.

Lim, E. L., \& Hew, K. F. (2013). Students' perceptions of the usefulness of an E-book with annotative and sharing capabilities as a tool for learning: A case study. Innovations in Education and Teaching International, 1-12. doi:10.1080/14703297.201.

Liu, Z. (2005). Reading behavior in the digital environment, changes in reading behavior over the past ten years. Journal of Documentation, 61(6), 700-712.

Liu, Z. (2012). Is it time for wider acceptance of e-textbooks? An examination of student reactions to e-textbooks. Chinese Journal of Library and Information Science (Quarterly), 5(3), 76-87.

Luik, P., \& Mikk, J. (2008). What is important in electronic textbooks for students of different achievement levels? Computers \& Education, 50(4), 1483-1494.

Mangen, A., Walgermo, B. R., \& Bronnick, K. (2013). Reading linear texts on paper versus computer screen: Effects on reading comprehension. International Journal of Educational Research, 58, 61-68.

Martin, A. (2009). The textbook of the future. Nature, 458(2), 568-570.

McFall, R. L., Dershem, H. L., \& Davis, D. (2006). Experiences using a collaborative electronic textbook: Bringing the guide on the side home with you. ACM SIGCSE Bulletin, 38(1), 339-343.

McGowan, M., Stephens, P., \& West, C. (2009). Student perceptions of electronic textbooks. Issues in Information Systems, 10(2), 459-465.

Murray, M. C., \& Perez, J. (2011). E-Textbooks are coming: Are we ready. Issues in Informing Science and Information Technology, 8, 49-60.

Nelson, Mark R. (2008a). E-books in higher education: Nearing the end of the era of hype? Educause Review, 43(2), 40-56.

Nelson, M. R. (2008b). E-books in higher education: Nearing the end of the era of hype? Educause Review, 43(2), 40.

Railean, E. (2012). Trends, issues and solutions in e-Book pedagogy. In T.-T. Goh (Ed.), E-Books and E-Readers for E-Learning (pp. 154-195). Wellington: Victoria Business School, Victoria University of Wellington.

Reynolds, R. (2011). Trends influencing the growth of digital textbooks in US higher education. Publishing Research Quarterly, 27(2), 178-187.

Rickman, J. T., von Holzen, R., Klute, P. G., \& Tobin, T. (2009). A campus-wide e-textbook initiative. Educause Quarterly, 32(2), n1.

Rockinson-Szapkiw, A. J., Courduff, J., Carter, K., \& Bennett, D. (2013). Electronic versus traditional print textbooks: A comparison study on the influence of university students' learning. Computers \& Education, 63, 259-266.

Shepperd, J. A., Grace, J. L., \& Koch, E. J. (2008). Evaluating the electronic textbook: Is it time to dispense with the paper text? Teaching of Psychology, 35(1), 2-5.

Simon, E. J. (2001). Electronic textbooks: A pilot study of student e-reading habits. Institute for CyberInformation.

Spanovic, S. (2010). Pedagogical aspects of e-textbooks. Odgojne Znanosti-Educational Sciences, 12(2), 459-470.

Sun, J., Flores, J., \& Tanguma, J. (2012). E-Textbooks and students' learning experiences. Decision Sciences Journal of Innovative Education, 10(1), 63-77.

Texas politics. (2008). Accessed August 12, 2013, from http://www.texaspolitics.laits.utexas.edu.

Vassiliou, M., \& Rowley, J. (2008). Progressing the definition of "e-book". Library Hi Tech, 26, $355-368$.

Weisberg, M. (2011). Student attitudes and behaviors towards digital textbooks. Publishing Research Quarterly, 27(2), 188-196.

Wilson, R., Landoni, M., \& Gibb, G. (2003). The WEB book experiments in electronic textbook design. Journal of Documentation, 59(4), 454-477.

Woody, W. D., Daniel, D. B., \& Baker, C. A. (2010). E-books or textbooks: Students prefer textbooks. Computers \& Education, 55(3), 945-948.

Young, J. R. (2010). To save students money, colleges may force a switch to e-textbooks, Chronicle of Higher Education. Retrieved October 24, 2010, from http://www.chronicle.com/article/The-End-ofthe-Textbook-as-We/125044/. 
Yuen, K. S., Chow, L., Simon, K. S., Cheung, K C Li, \& Eva, Y. M. T. (2012). Overcoming copyright hurdles in the development of learning materials in the digital era. Engaging Learners Through Emerging Technologies Communications in Computer and Information Science, 302, 190-200.

Xiaoqing Gu is a professor and head of the Department of Educational Information Technology, East China Normal University, China. Her research has focused primarily on ICT in education, including learning design, ICT-supported content design and development, ICT-integrated pedagogical innovation, computer-supported collaborative learning, and learning analytics to inform pedagogical design. She is editor-in-chief of the International Journal of Smart Technology and Learning, board member of the Journal of Computer Assisted Learning, associate editor of the Journal of Education and Learning, and reviewer of some academic journals such as Journal of Educational Technology \& Society and Journal of Computer-Mediated Communication.

Bian Wu received his Ph.D. degree from the University of Hong Kong. He is an assistant professor in the department of educational information technology, East China Normal University. His research interests include e-learning design and evaluation, problem-based learning, knowledge visualization and professional expertise development.

Xiaojuan Xu is a Research Assistant and graduate student in the department of educational information technology, East China Normal University. She received her Bachelor degree from Shanghai International Studies University. 